\title{
Load Transfer of Offshore Open-Ended Pipe Piles Considering the Effect of Soil Plugging
}

\author{
Junwei Liu ${ }^{1,2}$, Zhen Guo ${ }^{3, *}$ and Bo Han ${ }^{4}$ \\ 1 School of Civil Engineering, Qingdao University of Technology, Qingdao 266033, China; zjuljw@126.com \\ 2 China Postdoctoral research fellow, Hydraulic Engineering Post-Doctoral Scientific Research Station, \\ Zhejiang University, Hangzhou 310058, China \\ 3 Key Laboratory of Offshore Geotechnics and Material of Zhejiang Province, College of Civil Engineering and \\ Architecture, Zhejiang University, Hangzhou 310058, China \\ 4 School of Civil Engineering, Shandong University, Jinan 250061, China; bo.han@sdu.edu.cn \\ * Correspondence: nehzoug@163.com; Tel.: +86-137-3547-9107
}

Received: 25 July 2019; Accepted: 30 August 2019; Published: 8 September 2019

\begin{abstract}
Open-ended pipe piles have been increasingly used as the foundations for offshore structures. Considering the soil plugging effect, a novel analytical model is proposed in this paper to study the load transfer mechanism of open-ended pipe piles. A trilinear model for the external shaft friction was introduced, while a rigid plastic model was adopted to describe the load transfer at the pile-plug interface. Furthermore, an equilibrium equation of the soil plug was proposed, based on the hypothesis of a trilinear distribution of lateral earth pressure. The pile end resistance was analyzed by dividing it into two parts, i.e., the soil plug and pile annulus, the behaviors of which were described by the double broken line model. A calculation example was carried out to analyze the load transfer properties of the open-ended pipe piles. As a validation, similar load transfer processes of the open-ended pile were also captured in a newly built discrete element method model, mimicking the $100 \mathrm{~g}$ centrifuge testing conditions.
\end{abstract}

Keywords: open-ended pipe pile; plugging effect; load transfer; vertical bearing capacity; discrete element method

\section{Introduction}

In recent years, a large number of offshore structures have been under construction worldwide, such as offshore platforms, pipelines and wind farms. There are also some related theoretical and experimental researches about the responses of offshore structures in a complicated ocean environment [1-4]. Pipe piles have been generally used as the underlying supporting structures of these structures because of their satisfactory bearing capacity, light weight and outstanding workability [5-8]. In most cases, open-ended modes are employed to increase the ease of penetration [9-13]. However, during open-ended pile driving, part of the soil will be squeezed into the pipe pile and therefore a soil plug is formed. It is the formation of the soil plug that causes the load transfer of these open-ended pipe piles, rather different from that of closed-ended and solid ones, thus impacting the properties of their bearing capacity [14].

The bearing capacity of an open-ended pile is composed of external skin frictional resistance, annular toe resistance, as well as plug resistance (less of internal frictional resistance and base resistance on the soil plug). Frictional resistance is caused by the relative displacement between pile shaft and soil (soil plug). However, the mobilization mechanisms between external and internal skin frictions are different. During the initial loading, the external skin friction is gradually developed top-down as the pile descends, and the working load at the pile top is completely borne by the external skin 
friction. At this moment, no settlement occurs for the pile annulus end and no soil is squeezed into the pile pipe, thus the internal skin friction is not mobilized. As the loading increases, the applied load transfers to the soil below the pile annulus. Since the pile shaft has significantly larger rigidity than the soil plug, the soils below the pile annulus experience larger compression than that below the soil plug. This causes few soils to be squeezed into the pile pipe, even though the length of the soil plug keeps constant in most cases, i.e., the pile remains plugged during static testing $[1,15,16]$. During this stage, internal friction is gradually developed and soil plug resistance increases gradually. This complicated load transfer procedure suggests that the previous load transfer theoretical models $[12,17,18]$, which were derived from the solid pile, is not applicable for an open-ended pile.

Recently, the equilibrium analysis on soil plugs [1,7,14,19-21], as well as the experiments in a field and testing chamber $[8,10,22-24]$, have improved the understanding of the stress mobilization in the soil plugs of open-ended piles. Nevertheless, there are very few analytical models for an open-ended pipe pile $[14,15]$. This lack limits the accurate prediction of bearing capacity and settlement for open-ended piles by a theoretical approach. Therefore, taking the soil plugging effect into consideration, and using load transfer as the analytical method, this paper develops a theoretical approach for calculating the load transfer of open-ended pipe piles. A calculation example is presented to exhibit the load transfer characteristic of an open-ended pile subjected to vertical loading and its difference compared to a closed-ended pile. As a validation, a numerical two-dimensional discrete element method (DEM) model using PFC software which was developed by the ITASCA consulting group was built to reveal this load transfer process by applying axial loading to an open-ended pile jacked into sandy soil.

\section{Load Transfer Model of Open-Ended Pipe Piles}

\subsection{Computational Assumptions}

As soil plug is a major factor that affects the development of bearing capacity of open-ended pipe piles, with the interactions between the soil plug and pile annulus being crucial. In order to simplify the calculations, the effect of the pile annulus and internal soil plug was considered separately. The open-ended pipe pile was defined as a kind of "pile-in-pile" system, i.e., the pile annulus as the "outer pile" (Figure 1b) and the soil plug as the "inner pile" (Figure 1c). Thus, the pile annulus and soil plug can be analyzed separately. At the same time, they experienced interactive coupling and together constrained the development of the bearing capacity of the pipe pile. The external skin frictional resistance of the inner pile (soil plug) was the internal skin friction of the outer pile (pile annulus).

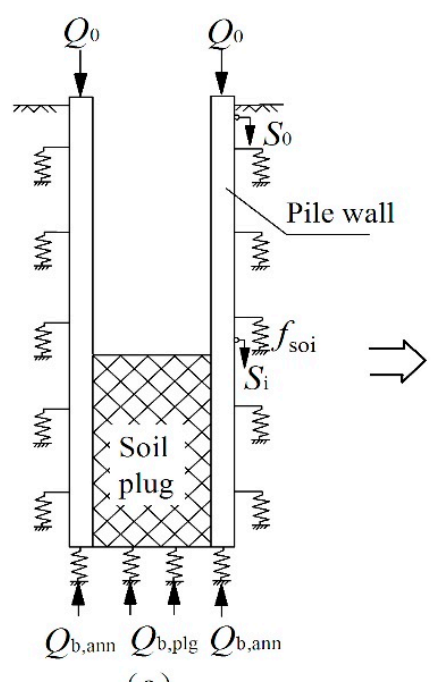

(a)

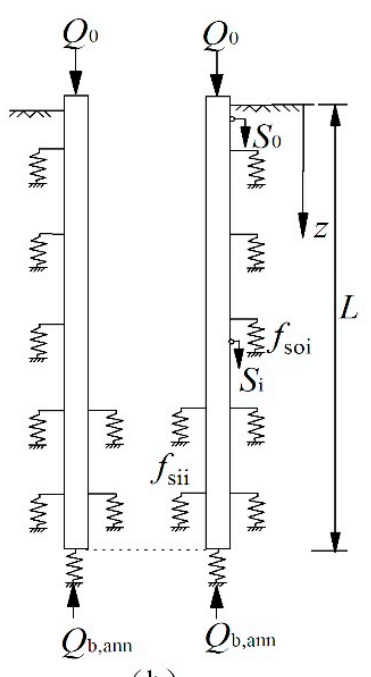

(b)

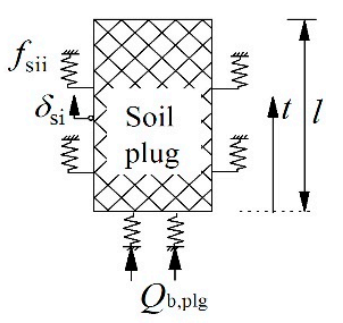

(c)

Figure 1. Load transfer diagram for open-ended pipe pile. ((a) Open-ended pile defined as "pile in pile" system, (b) pile annulus defined as "outer pile", (c) soil plug defined as "inner pile".). 
In these calculations, it was assumed that the load at annulus end $Q_{\mathrm{b}, \text { ann }}$ transferred through the pile annulus (outer pile), and the load at the soil plug end $Q_{\mathrm{b} \text {,plg }}$ transferred through the soil plug and then induced the internal skin friction $f_{\mathrm{si}}$. The derivation was based on the following assumptions: (a) The material behavior of the pile shaft was assumed to be linearly elastic under vertical loading; (b) pile tip settlement was only induced by the loads on the pile tip; (c) the soil was homogeneous. The assumptions (a) and (b) are consistent of those in the previous load transfer theoretical models for solid pile $[17,18,25]$. Assumption (c) was just used to simplify this analytical model.

According to the force equilibrium of a pile unit, the basic differential equation for load transfer can be written as [25], which was applicable to the external pile annulus (outer pile) and soil plug (inner pile), as shown in Figure 1.

$$
E_{\mathrm{p}} A_{\mathrm{p}} \frac{\mathrm{d}^{2} S(z)}{\mathrm{d} z^{2}}-f_{\mathrm{s}}(z) U=0
$$

where $E_{\mathrm{p}}$ is the elastic modulus of pile $(\mathrm{kPa}) ; A_{\mathrm{p}}$ is the area of cross-section of pile $\left(\mathrm{m}^{2}\right) ; z$ is the depth from ground surface; $\mathrm{dz}$ is the unit change of depth; $S(z)$ is the relative displacement of pile to surrounding soil medium $(\mathrm{m}) ; f_{\mathrm{s}}(z)$ is the unit side friction $(\mathrm{kPa})$, which is the friction of the soil surrounding the pile annulus and the annulus soil plug for the outer pile and inner pile, respectively, in the herein "pile-in-pile" analytical model; $U$ is the circumference of the pile cross-section $(\mathrm{m})$. It should be noted that compared to the resistances of soils, the weight of the hollow pipe pile was much smaller and therefore its contribution to the force equilibrium was ignored for simplicity.

The relation between the axial force of pile $P(z)$, unit side friction $f_{\mathrm{s}}(z)$ and the relative displacement of pile to surrounding medium $S(z)$ was as follows [25]:

$$
\left.\begin{array}{c}
\frac{\mathrm{d} S(z)}{\mathrm{d} z}=-\frac{P(z)}{E_{\mathrm{p}} A_{\mathrm{p}}} \\
\frac{\mathrm{d} P(z)}{\mathrm{d} z}=-2 \pi r_{0} f_{\mathrm{s}}(z)
\end{array}\right\}
$$

where $r_{0}$ is the radius of pile. It should be noted that the above equations were common for all the piles. However, the parameters were valued respectively for the external pile annulus (outer pile) and soil plug (inner pile) in the current model of an open-ended pile.

\subsection{Load Transfer Model of Outside Pile Annulus}

A trilinear model is used for the load transfer of the pile annulus and surrounding soil, as shown in Figure 2, and the load transfer function was expressed in Equation (3), as follows:

$$
f_{\text {se }}=\left\{\begin{array}{cc}
\lambda_{1} S & \left(S \leq S_{1}\right) \\
\lambda_{1} S_{1}+\lambda_{2}\left(S-S_{1}\right) & \left(S_{1}<S \leq S_{\mathrm{u}}\right) \\
\lambda_{1} S_{1}+\lambda_{2}\left(S_{\mathrm{u}}-S_{1}\right)=f_{\text {seu }} & \left(S>S_{\mathrm{u}}\right)
\end{array}\right.
$$

where $f_{\text {se }}(z)$ is the external skin friction of pipe pile (Pa); $S(z)$ is the relative displacement of pile annulus to surrounding soil $(\mathrm{m})$, which is descending in amount under the assumption of no vertical movement of the surrounding soil; $\lambda_{1}$ and $\lambda_{2}$ are the coefficients of shearing rigidity of the surrounding soil in the elastic and plastic stages, respectively $(\mathrm{Pa} / \mathrm{m}) ; S_{1}$ is the limit displacement at the end of the elastic stage $(\mathrm{m}) ; S_{\mathrm{u}}$ is the limit displacement when side friction achieves its maximum at the end of the plastic stage (m). To determine load transfer function, four parameters are needed- $\lambda_{1}, \lambda_{2}, S_{1}$ (or $f_{\text {se1 }}$ ) and $S_{u}$ (or $f_{\text {seu }}$ ). Furthermore, it is assumed that the coefficients of shearing rigidity in elastic and plastic stage $\lambda_{1}$ and $\lambda_{2}$ are only dependent on the material of pile and soil, but independent of depths. Hence they 
remain the same in homogeneous soil. Let $f_{\text {se1 }}=\eta f_{\text {seu }}=\eta k z$ ( $\eta$ is a constant). Boundary and limit displacements were obtained as follows [25]:

$$
\begin{gathered}
S_{1}=\frac{\eta k z}{\lambda_{1}} \\
S_{\mathfrak{u}}=\frac{\eta k z}{\lambda_{1}}+\frac{(1-\eta) k z}{\lambda_{2}}
\end{gathered}
$$

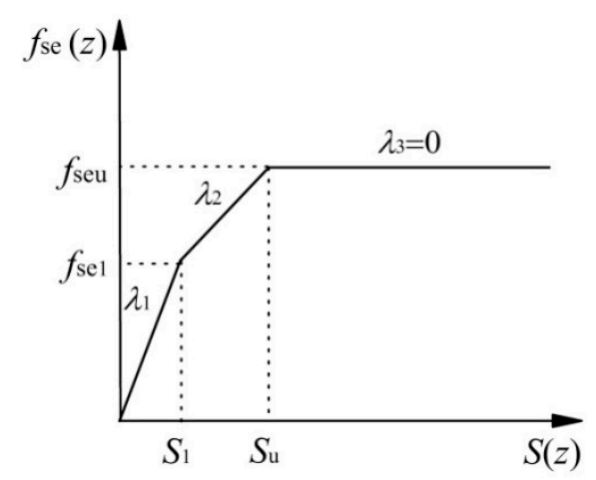

Figure 2. Load transfer trilinear model of pile-soil interface.

Parameter $k$ is the stiffness coefficient of shaft friction along depth $(\mathrm{Pa} / \mathrm{m})$. The values of $\lambda_{1}, \lambda_{2}$ and $\eta$ can be obtained from field measurements. $\lambda_{1}$ can also be approximated using a close-theoretical solution by the shearing displacement method [17] as follows:

$$
\lambda_{1}=\frac{G_{s}}{\zeta r_{0}}
$$

where $\zeta=\ln \left(r_{\mathrm{m}} / r_{0}\right), r_{\mathrm{m}}=2.5 L\left(1-v_{\mathrm{s}}\right) ; G_{\mathrm{s}}$ is the shearing modulus of the surrounding soil; $r_{0}$ is pile radius; $v_{\mathrm{s}}$ is the Poisson's ratio of the surrounding soil; $L$ is the pile length. The limit side friction $f_{\text {seu }}$ is approximated to increase linearly with depth [17], which can be expressed using the $\beta$-method:

$$
f_{\text {seu }}=K \sigma_{v}^{\prime} \tan \delta=K \gamma^{\prime} z \tan \delta=k z
$$

where $\gamma^{\prime}$ is the effective unit weight of the surrounding soil $\left(\mathrm{kN} / \mathrm{m}^{3}\right) ; K$ is the lateral pressure coefficient of surrounding soil; $\delta$ is the friction angle between the pile annulus and surrounding soil $\left(^{\circ}\right)$.

For the discussions on the values of parameters $K$ and $\delta$ of the outside pile annulus, please refer to the author's previous work [26], in which the pile-soil friction angle $\delta$ is $0.9 \varphi^{\prime}$ (where $\varphi^{\prime}$ is the internal friction angle of soil). As for the value of external lateral pressure coefficient $K$, we believe it is closely related to the amount of soil compaction of the open-ended pipe piles [27,28], which can be directly reflected by the soil plug length rate (PLR). PLR is defined as the ratio of the soil plug length to the penetration depth at the completion of pile installation. Following the work by Yu and Zhang [28], a linear model was used to express how the coefficient $K$ varies with PLR

$$
K=(2.0-0.6 \mathrm{PLR}) K_{0}
$$

where PLR, if not known, for an open-ended steel pile may be estimated by an empirical relationship proposed by Yu and Zhang [28].

$$
\operatorname{PLR}=\left(\frac{D_{\mathrm{i}}}{100}\right)^{0.15}
$$


where $D_{\mathrm{i}}$ is the inside radius of the pile. For normally consolidated sandy soil, the relationship between the at-rest earth pressure coefficient $K_{0}$ and the frictional angle of soil $\varphi^{\prime}$ was as follows:

$$
K_{0}=1-\sin \varphi^{\prime}
$$

\subsection{Load Transfer Model inside the Pile Annulus}

There is no research to date on the load transfer model for the inner side of pile annulus. Randolph [29] thought that the relative displacement required by the inner side of a steel pile to develop the internal skin friction is only $0.2 \% \sim 0.5 \%$ of the pile radius. Therefore, Randolph et al. [6] neglected this relative displacement in his theoretical reasoning, assuming a rigidity model for the development of internal skin frictional resistance. A rigidity plastic expression was also introduced here to describe the load transfer at the pile-plug interface:

$$
f_{\mathrm{si}}(t)=\beta \sigma_{v s}^{\prime}=K_{s} \sigma_{v s}^{\prime} \tan \delta_{i}
$$

where $f_{\text {si }}$ is the unit internal friction of the open-ended pile; $K_{\mathrm{s}}$ is the lateral pressure coefficient of the soil plug; $\sigma_{v s}^{\prime}$ is the effective vertical stress at various height $t$, as shown in Figure $1 \mathrm{c} ; \delta_{i}$ is the friction angle between the soil plug and the inner side of the pile annulus. There is already research showing that the shearing failure plane of the inner side of the annulus occurs inside soil [30]. Hence, if the change in density of the compacted soil plug is neglected, the value of $\delta_{\mathrm{i}}$ can be approximated by the friction angle of the soil outside pile. Model tests [31-33] and results of numerical analysis [34] showed that, because of the existence of "soil arching effect", the lateral pressure coefficient of the inner side of pile is greater than that of the outer side, achieving a maximum value between 1 to 2 radius in the vicinity of pile end, as shown in Figure 3. It was expressed as a trilinear model, as shown in Figure 3 and Equation (12).

$$
K_{\mathrm{s}}= \begin{cases}K_{\mathrm{smax}} & \left(t \leq D_{\mathrm{i}}\right) \\ K_{\mathrm{smax}}-\frac{K_{\mathrm{smax}}-K_{\operatorname{smin}}}{4 d}\left(t-D_{\mathrm{i}}\right) & \left(D_{\mathrm{i}}<t \leq 5 D_{\mathrm{i}}\right) \\ K_{\mathrm{smin}} & \left(5 D_{\mathrm{i}}<t \leq h\right)\end{cases}
$$

where $h$ is the effective height of the soil plug; $K_{\text {smax }}$ and $K_{\text {smin }}$ are the maximum and minimum lateral pressure coefficients of the soil plug within the effective height.

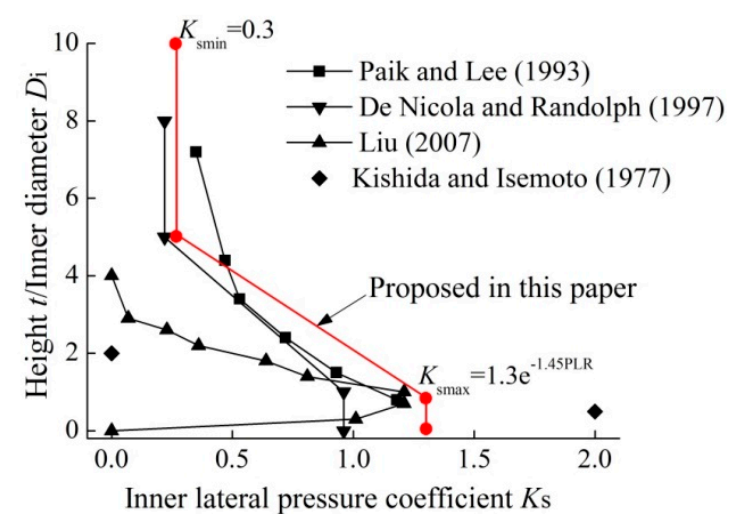

Figure 3. Trilinear model for the distribution of lateral pressure coefficient for the soil plug.

De Nicola and Randolph [33] suggested that for sandy soil, $K_{\text {smax }}$ can be expressed as a function of soil relative density $\operatorname{Dr}\left(\right.$ in $\%$ ), i.e., $K_{\mathrm{smax}}=D \mathrm{r} / 100$. Lehane and Gavin [23] showed in their research that $K_{\text {smax }}$ can be as high as 1.3 , and $K_{\mathrm{smin}}$ as low as 0.3 . The latter is the value for $K_{\mathrm{smin}}$ in our computation, but $K_{\text {smax }}$ is not a constant and is related closely to the plug length ratio (PLR) [28], as expressed in the exponential function below:

$$
K_{\mathrm{smax}}=1.3 \exp (-1.45 \mathrm{PLR})
$$




\subsection{Load Transfer Model for Pile Tip}

Neglecting the change in properties of soil under the pile tip, the same double broken line model (Figure 4) was used to describe the load transfer of the annulus end and soil plug end, which was expressed as follows [25]:

$$
q_{\mathrm{b}}=\left\{\begin{array}{cc}
k_{1} S_{\mathrm{b}} & \left(S_{\mathrm{b}} \leq S_{\mathrm{bu}}\right) \\
k_{1} S_{\mathrm{bu}}+k_{2}\left(S_{\mathrm{b}}-S_{\mathrm{bu}}\right) & \left(S_{\mathrm{b}}>S_{\mathrm{bu}}\right)
\end{array}\right.
$$

where $q_{\mathrm{b}}$ is the unit vertical stress at pile end $(\mathrm{Pa}) ; k_{1}$ and $k_{2}$ are the normal rigidity coefficients in the elastic stage and plastic stage, respectively $(\mathrm{Pa} / \mathrm{m}) ; S_{\mathrm{b}}$ is the settlement of the pile end $(\mathrm{m}) ; S_{\mathrm{bu}}$ is the limit displacement between the elastic and plastic stages $(\mathrm{m})$.

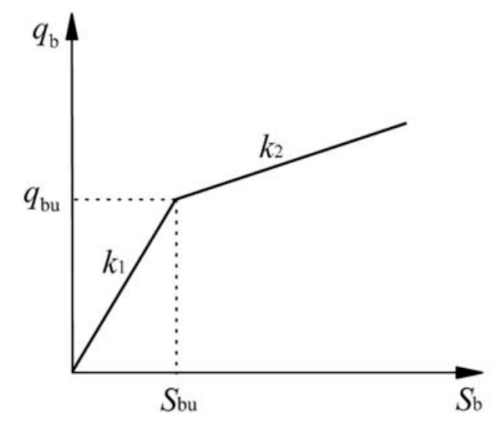

Figure 4. Load transfer model for pile tip.

$k_{1}$ can be calculated as follows [17]:

$$
k_{1}=\frac{4 G_{\mathrm{b}}}{\pi r_{0}\left(1-v_{\mathrm{b}}\right)}
$$

where $G_{\mathrm{b}}$ and $v_{\mathrm{b}}$ are the shearing modulus and Poisson's ratio of the soil below the pile annulus.

$k_{2}$ can be implied from the load-settlement curve of a single pile. Under a large load, the load-settlement curve remained a straight line, which indicated that the sliding regime of the surrounding soil had expanded to the whole range of the pile shaft, causing the total frictional resistance to stop increasing, with the working load $P_{0}$ at the pile head being completely borne by pile end resistance. The settlement of the pile end was the result of subtracting the compaction amount of pile shaft $\Delta S$ from the descending amount of pile head $S_{0}$. When the whole pile shaft is in sliding stage, the compaction amount can be solved as follows:

$$
\Delta S=\frac{\Delta P_{0} L}{E_{\mathrm{p}} A_{\mathrm{p}}}
$$

Hence, substituting the three quantities gives $k_{2}$ :

$$
k_{2}=\frac{\Delta P_{0}}{S_{0}-\Delta S}=\frac{k_{\mathrm{t}}}{1-\frac{L}{E_{\mathrm{p}} A_{\mathrm{p}}} k_{\mathrm{t}}}
$$

where $k_{\mathrm{t}}=\Delta P_{0} / \Delta S_{0}$ is the slope of the steep dipping section of the load-settlement curve; $E_{\mathrm{p}}$ and $A_{\mathrm{p}}$ are the elastic modulus and cross-section area of the pile, respectively.

\section{Load Transfer Analysis on Open-Ended Pipe Piles}

\subsection{Load Transfer Analysis outside Pile Annulus}

With the settlement of the pile, the friction offered by the pile annulus was mobilized generally. A trilinear load transfer model was applied. The pile-soil interface had three states: (i) elastic stage, (ii) plastic stage, (iii) sliding stage, as illustrated in Figure 5 below. 


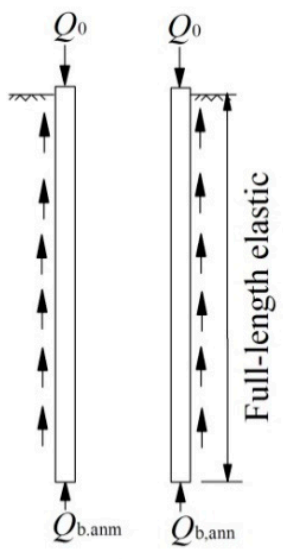

(i)

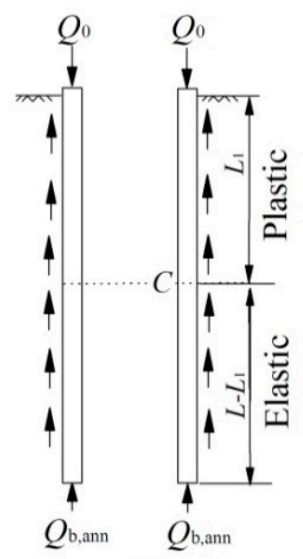

(ii)

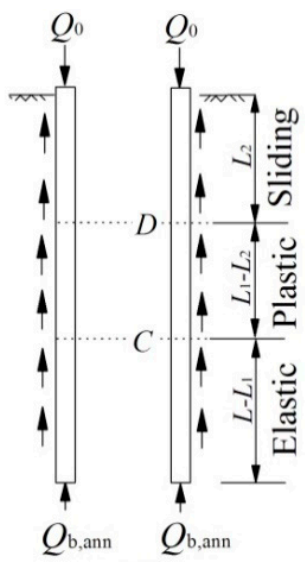

(iii)

Figure 5. Calculation model for surrounding soil. ((i) elastic stage, (ii) plastic stage, (iii) sliding stage).

(1) All surrounding soil in the elastic load transfer stage.

When the working load at a single pile head was small, the settlement of the pile shaft was small, and the surrounding soil was in a full-length elastic state. From the load transfer trilinear model (Figure 2) and basic function (Equation (3)), the load transfer function and the boundary conditions were derived as follows [25]:

$$
\left.\begin{array}{l}
E_{\mathrm{p}} A_{\mathrm{p}} \frac{\mathrm{d}^{2} S(z)}{d z^{2}}-\lambda_{1} S(z) U=0 \\
\left.E_{\mathrm{p}} A_{\mathrm{p}} \frac{\mathrm{d} S(z)}{d z}\right|_{z=L}=-P_{\mathrm{b}, \mathrm{ann}} \\
\left.S(z)\right|_{z=L}=S_{\mathrm{b}, \mathrm{ann}}
\end{array}\right\}
$$

Solving the above equations to get

$$
\begin{gathered}
S(z)=\frac{1}{2} \mathrm{e}^{-M_{1}(L-z)}\left(S_{b, \mathrm{ann}}-\frac{P_{\mathrm{b}, \text { ann }}}{M_{1} E_{\mathrm{p}} A_{\mathrm{p}}}\right)+\frac{1}{2} \mathrm{e}^{M_{1}(L-z)}\left(S_{\mathrm{b}, \mathrm{ann}}+\frac{P_{\mathrm{b}, \mathrm{ann}}}{M_{1} E_{\mathrm{p}} A_{\mathrm{p}}}\right) \\
P(z)=-E_{\mathrm{p}} A_{\mathrm{p}} M_{1}\left[\frac{1}{2} e^{-M_{1}(L-z)}\left(S_{\mathrm{b}, \mathrm{ann}}-\frac{P_{\mathrm{b}, \mathrm{ann}}}{M_{1} E_{\mathrm{p}} A_{\mathrm{p}}}\right)\right]-\frac{1}{2} e^{M_{1}(L-z)}\left(S_{\mathrm{b}, \mathrm{ann}}+\frac{P_{\mathrm{b}, \text { ann }}}{M_{1} E_{\mathrm{p}} A_{\mathrm{p}}}\right)
\end{gathered}
$$

where

$$
M_{1}=\sqrt{\frac{\lambda_{1} U}{E_{\mathrm{p}} A_{\mathrm{p}}}}
$$

(2) Part of the surrounding soil in the elastic stage

As the load at pile head increased, settlement increased as well. When the settlement of pile head met the condition $S_{0}>S_{1}(0)$, the surrounding soil gradually moved top-down into the plastic stage. Let the load and settlement at cross-section $C$ be $P_{c}$ and $S_{c}$, respectively. Then, for the pile shaft in the plastic stage, the load transfer differential equation and boundary conditions are as follows:

$$
\left.\begin{array}{l}
E_{\mathrm{p}} A_{\mathrm{p}} \frac{\mathrm{d}^{2} S(z)}{\mathrm{d} z^{2}}-\left[\lambda_{1} S_{1}+\lambda_{1}\left(S-S_{1}\right)\right] U=0 \\
\left.E_{\mathrm{p}} A_{\mathrm{p}} \frac{\mathrm{d} S(z)}{\mathrm{d} z}\right|_{z=L_{1}}=-P_{\mathrm{c}} \\
\left.S(z)\right|_{z=L_{1}}=S_{\mathrm{c}}
\end{array}\right\}
$$

Solving the above equations to get

$$
\left\{\begin{array}{l}
S \\
P
\end{array}\right\}=\operatorname{Tp}(z)\left\{\begin{array}{l}
S_{\mathrm{c}} \\
P_{\mathrm{c}}
\end{array}\right\}-T a(z)
$$




$$
\begin{gathered}
\operatorname{Tp}(z)=\left[\begin{array}{cc}
\cosh \left[M_{2}\left(L_{1}-z\right)\right] & \sinh \left[M_{2}(L-z)\right] /\left(E_{\mathrm{p}} A_{\mathrm{p}} M_{2}\right) \\
\left(E_{\mathrm{p}} A_{\mathrm{p}} M_{2}\right) \sinh \left[M_{2}\left(L_{1}-z\right)\right] & \cosh \left[M_{2}\left(L_{1}-z\right)\right]
\end{array}\right] \\
\operatorname{Ta}(z)=\frac{\lambda_{2}-\lambda_{1}}{\lambda_{2} \lambda_{1}}\left[\begin{array}{c}
k\left\{\sinh \left[M_{2}\left(L_{1}-z\right)\right] / M_{2}+z-L_{1} \cosh \left[M_{2}\left(L_{1}-z\right)\right]\right\} \\
k E_{\mathrm{p}} A_{\mathrm{p}}\left\{\cosh \left[M_{2}\left(L_{1}-z\right)\right]-L_{1} M_{2} \sinh \left[M_{2}\left(L_{1}-z\right)\right]-1\right\}
\end{array}\right] \\
M_{2}=\sqrt{\frac{\lambda_{2} U}{E_{\mathrm{p}} A_{\mathrm{p}}}}
\end{gathered}
$$

(3) Part of the surrounding soil in the sliding stage

When the descending amount of pile head met the condition $S_{0}>S_{\mathrm{u}}(0)$, the surrounding soil gradually moved top-down into the sliding stage. The differential equation for sliding stage was as follows:

$$
\left.\begin{array}{l}
E_{\mathrm{p}} A_{\mathrm{p}} \frac{\mathrm{d}^{2} S(z)}{\mathrm{d} \mathrm{d}^{2}}-f_{\mathrm{se}} U=0 \\
\left.E_{\mathrm{p}} A_{\mathrm{p}} \frac{\mathrm{d}(z)}{\mathrm{d} z}\right|_{z=L_{2}}=-P_{\mathrm{D}} \\
\left.S(z)\right|_{z=L_{2}}=S_{\mathrm{D}}
\end{array}\right\}
$$

Solving the above equations to get

$$
\left\{\begin{array}{l}
S \\
P
\end{array}\right\}=T c(z)\left\{\begin{array}{l}
S_{\mathrm{D}} \\
P_{\mathrm{D}}
\end{array}\right\}+T c a(z)
$$

where

$$
\begin{gathered}
T c(z)=\left[\begin{array}{cc}
1 & \left(L_{2}-z\right) /\left(E_{\mathrm{p}} A_{\mathrm{p}}\right) \\
0 & 1
\end{array}\right] \\
T a(z)=\frac{U_{\mathrm{p}}}{E_{\mathrm{p}} A_{\mathrm{p}}}\left[\begin{array}{c}
k\left(z^{3}-3 L_{2}^{2} z+2 L_{2}^{3}\right) / 6 \\
k E_{\mathrm{p}} A_{\mathrm{p}}\left(L_{2}^{2}-z^{2}\right) / 2
\end{array}\right]
\end{gathered}
$$

\subsection{Load Transfer Analysis inside the Pile Annulus}

During loading, the water in the soil plug gradually drained out, and the elastic modulus $E_{\mathrm{S}}$ of the soil plug changed accordingly, yet changing laws are difficult to determine. Hence, the basic load transfer function was hardly applicable. On the other hand, the load transfer between the pile internal skin and the soil plug confirmed the rigidity-plasticity model, i.e., the development of internal skin friction was not affected by relative displacement. Therefore, neither soil plug compaction nor relative displacement needed to be taken into consideration, but only the force balance of the soil plug.

The part of the soil plug above effective height $h$ was treated as overload. The force analysis of the soil plug unit is shown in Figure 6b, and coordinate $t$ (the upwards distance from pile end) in Figure 6a. Hence, the basic expression for the equilibrium equation based on effective stress was as follows:

$$
\frac{\mathrm{d} \sigma_{v s}^{\prime}}{\mathrm{d} z}=-\gamma^{\prime}-\frac{4}{D_{\mathrm{i}}} f_{\mathrm{si}}=-\gamma_{\mathrm{s}}^{\prime}-\frac{4}{D_{\mathrm{i}}} \beta \sigma_{v s}^{\prime}
$$

where $\beta$ can be expressed using Equations (11) and (12). Since the side pressure coefficient was modelled by a trilinear function, as seen in Figure $6 c$, the solutions to the equilibrium equation of the soil plug have also been split into three sections as well. 


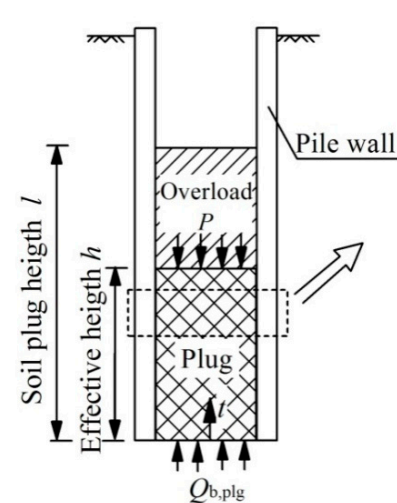

(a)

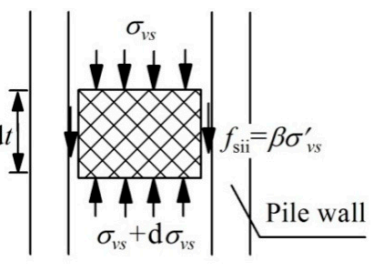

(b)

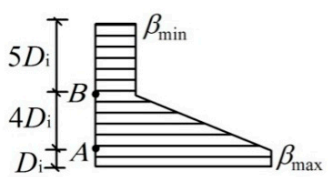

(c)

Figure 6. Stress conditions within the soil plug ((a) equilibrium of soil plug, (b) equilibrium of soil plug unit, (c) side pressure coefficient model of soil plug).

(1) $0 \leq t<D_{\text {i }}$

With the equilibrium equation of the soil plug becoming

$$
\frac{\mathrm{d} \sigma_{v s}^{\prime}}{\mathrm{d} x}+\frac{4 K_{\max } \tan \delta_{\mathrm{i}}}{D_{\mathrm{i}}} \sigma_{v s}^{\prime}=-\gamma_{\mathrm{s}}^{\prime}
$$

Considering boundary conditions when $\mathrm{x}=0, \sigma_{v s}^{\prime}=q_{\mathrm{b} \text {,plg }}$ and denoting $N_{1}=4 K_{\max } \tan \delta_{\mathrm{i}} / D_{\mathrm{i}}$ gave the vertical effective stress at various heights:

$$
\sigma_{v s}^{\prime}=q_{\mathrm{b}, \mathrm{plg}}+\left(\mathrm{e}^{-N_{1} x}-1\right)\left(q_{\mathrm{b}, \mathrm{plg}}+\frac{\gamma^{\prime}}{N_{1}}\right)
$$

where $q_{\mathrm{b}, \text { plg }}$ is the vertical stress at soil plug end.

(2) $D_{\mathrm{i}} \leq t<5 D_{\mathrm{i}}$

The equilibrium function for the soil plug was

$$
\frac{\mathrm{d} \sigma_{v s}^{\prime}}{\mathrm{dx}}+\left[\frac{\left(5 K_{\mathrm{smax}}-0.3\right) \tan \delta_{\mathrm{i}}}{D_{\mathrm{i}}}-\frac{\left(K_{\mathrm{smax}}-0.3\right) \tan \delta_{\mathrm{i}}}{D_{\mathrm{i}}^{2}} t\right] \sigma_{v s}^{\prime}=-\gamma_{\mathrm{s}}^{\prime}
$$

The function above has no analytic solutions. Now let $(x)=\int e^{N_{2} t-\frac{1}{2} N_{3} t^{2}} \mathrm{~d} t, N_{2}=$ $\left(5 K_{\mathrm{smax}}-0.3\right) \tan \delta_{\mathrm{i}} / D_{\mathrm{i}}, N_{3}=\left(K_{\max }-0.3\right) \tan \delta_{\mathrm{i}} / D_{\mathrm{i}}{ }^{2}$ and consider boundary conditions $t=D_{\mathrm{i}}, \sigma^{\prime}{ }_{\mathrm{v}}$ $=\sigma_{\text {vsA }}^{\prime}$, where $\sigma_{\text {vsA }}^{\prime}$ can be obtained by substituting $t=D_{\mathrm{i}}$ into Equation (33). Hence, the vertical effective stress of soil plug can be expressed as follows:

$$
\sigma_{v s}^{\prime}=\sigma_{v s A}^{\prime} \mathrm{e}^{-N_{2}\left(t-D_{\mathrm{i}}\right)+\frac{1}{2} N_{3}\left(t^{2}-D_{\mathrm{i}}^{2}\right)}-\mathrm{e}^{-N_{2} t+\frac{1}{2} N_{3} t^{2}} \gamma^{\prime}[T(t)-T(\mathrm{~d})]
$$

where

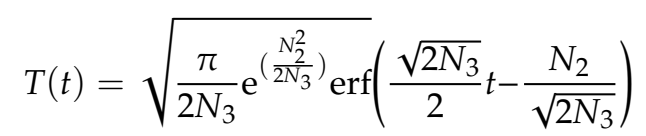

where erf is the Gaussian error function.

(3) $5 D_{\mathrm{i}} \leq t<10 D_{\mathrm{i}}$

The equilibrium function of the soil plug was

$$
\frac{\mathrm{d} \sigma_{v s}^{\prime}}{\mathrm{d} x}+\frac{1.2 \tan \phi}{D_{\mathrm{i}}} \sigma_{v s}^{\prime}=-\gamma_{s}^{\prime}
$$

where the parameters $\sigma_{v s}^{\prime}, D_{\mathrm{i}}$ and $\phi$ are the effective vertical stress, inside radius of the pile and pile-plug friction angle, respectively. Let $N_{4}=1.2 \tan \phi / \mathrm{d}$, and consider boundary conditions $\mathrm{x}=5 D_{\mathrm{i}}$, 
$\sigma_{\text {vs }}^{\prime}=\sigma_{\text {vsB }}^{\prime}$, where $\sigma_{\text {vsB }}^{\prime}$ can be obtained by substituting $t=5 D_{\mathrm{i}}$ into Equation (35). Hence the vertical effective stress for this section was expressed as follows:

$$
\sigma_{v s}^{\prime}=\sigma_{v B}^{\prime}+\left(\mathrm{e}^{-N_{4} t}-1\right)\left(\sigma_{v B}^{\prime}+\frac{\gamma^{\prime}}{N_{4}}\right)
$$

The part of soil plug above the effective height can be treated as over-load. Solving the equation below obtains $t$, which is actually the effective height

$$
\sigma_{v s}^{\prime}=\gamma^{\prime}(l-t)
$$

The vertical stress at soil plug end $q_{\mathrm{s}, \mathrm{plg}}$ depended on the settlement of soil below the soil plug end $S_{\mathrm{b}, \text { plg }}$, but $S_{\mathrm{b}, \mathrm{plg}}$ is not equal to the settlement of pile annulus end $S_{\mathrm{b}, \mathrm{ann}}$. In order to stimulate the friction on the inner side of the annulus, there must be relative displacement between the soil plug and pile wall, which means that a volume of soil will be squeezed into the pile, i.e., $S_{\mathrm{b}, \text { plg }}$ is less than $S_{\mathrm{b}, \text { ann }}$. To determine $S_{\mathrm{b}, \mathrm{plg}}$, the loading mechanic process can be considered as an extension of pile driving at its ending moment. Therefore, the final filing ratio (FFR) of the soil plug, which was defined as the ratio between the increment of the soil plug length and the increment of pile penetration depth over the final stages of pile installation, was adopted here. Then, the relative displacement at the soil plug end $w_{0}$, and descending amount of the soil below the soil plug $S_{\mathrm{b}, \mathrm{plg}}$, at various settlement of pile annulus $S_{\mathrm{b}, \text { ann }}$ can be computed

$$
\begin{aligned}
S_{\mathrm{b}, \mathrm{plg}} & =(1-\mathrm{FFR}) S_{\mathrm{b}, \mathrm{ann}} \\
w_{0} & =\mathrm{FFR} \cdot S_{\mathrm{b}, \mathrm{plg}}
\end{aligned}
$$

A double broken line model was employed to describe the load transfer at the soil plug end. Substituting Equation (36) into Equation (14) gives us vertical effective stress of the soil plug, and from Equation (11) the distribution of internal skin friction of pile can be obtained. With Equations (42) and (43), the axial force and compaction amount of pile shaft, caused by internal skin friction, can be derived as follows:

$$
\begin{gathered}
Q_{\mathrm{plg}}(t)=\pi D_{\mathrm{i}} \int_{0}^{h} f_{\mathrm{siu}} d t \\
S_{\mathrm{plg}}(t)=\frac{1}{E_{\mathrm{p}} A_{\mathrm{p}}} \int_{0}^{h} Q_{\mathrm{plg}}(t) d t
\end{gathered}
$$

\subsection{Computation Steps}

(1) First it was assumed that there was a small displacement at the annulus end $S_{\mathrm{b}, \text { ann1 }}$, and from Equation (14) pile annulus end resistance $P_{\mathrm{b}, \mathrm{ann} 1}$ was determined.

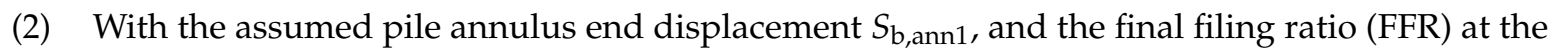
moment when pile driving ends, we used Equation (40) and Equations (14) to determine the descending amount of soil below the soil plug end $S_{\mathrm{b}, \mathrm{plg} 1}$ and vertical stress at the soil plug end $q_{\mathrm{b}, \mathrm{plg} 1}$, as well as Equation (39) to compute the effective height of soil plug $h$.

(3) From Equations (33), (35) and (38), the vertical effective stress $\sigma^{\prime}{ }_{v s}$ at various heights within the effective height $h$ can be calculated, so that from Equation (11) the internal skin friction $f_{\text {si, }}$, and hence from Equations (42) and (43), the resulting axial force and compaction are obtained.

(4) From Equations (19), (20), (23) and (28), the compute axial force and pile shaft displacement was found to be caused by the external skin friction corresponding to displacement of pile annulus $S_{\mathrm{b}, \mathrm{ann} 1}$.

(5) By superposing the previous two steps, we obtained the distribution of axial force and settlement of open-ended pipe pile shaft under both inner and outer side frictions, as well as the load and settlement. 
(6) As displacement at pile end $S_{\mathrm{b}, \text { ann }}$ increased, the load-settlement curve of the pile top and the stress distribution of the pile draft were obtained.

When analyzing layered soils, the pile draft can be split into a series of pile sections based on layers of foundation soil. From existing research, it is known that there is corresponding relation between layers of soil plug and layered soils. The thickness of each layer can be determined by how IFR (incremental filling ratio) varies when pile penetrates, and the soil plug can be split into a series of soil plug sections for computations, as shown in Figure 7. Each calculation pile section and soil plug section was analyzed following the computation steps of homogeneous soil. The stress and displacement of the head of the calculation section below were found at the bottom of the calculation section immediately above. Hence, the distribution of axial force of the full-length pile shaft, as well as its load-settlement curve, can be obtained.

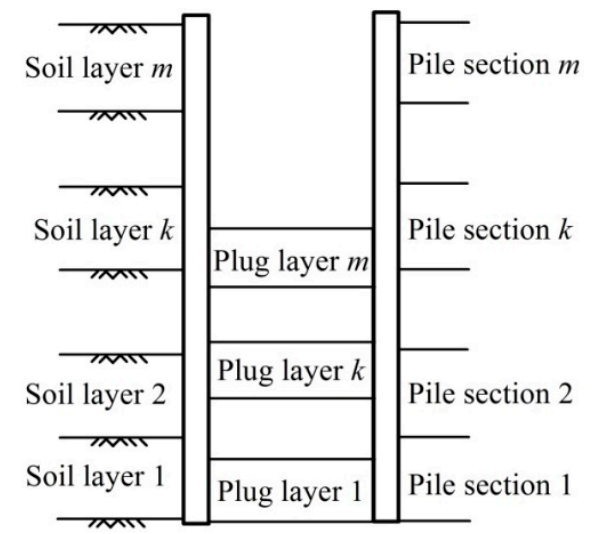

Figure 7. Computation diagram of the pipe pile in layered soils.

\section{Calculation Example}

We used a calculation example to carry out a comparison analysis on the properties of load transfer of open-ended concrete pipe piles. In this example, concrete pipe piles with an outer diameter of 600 $\mathrm{mm}$ and a wall thickness of $110 \mathrm{~mm}$ were deployed, whose pile shaft elastic modulus $E_{\mathrm{p}}$ was $3.8 \times 10^{4}$ $\mathrm{MPa}$. Surrounding soil and soil at the pile end were the same as the homogeneous one; there was no bearing stratum at the pile end. We took soil plug rate (PLR) as 0.3, i.e., the length of soil plug was $6.0 \mathrm{~m}$. Let each level of loading at the pile be $200 \mathrm{kN}$, and configure other parameters as in Figure 8 .

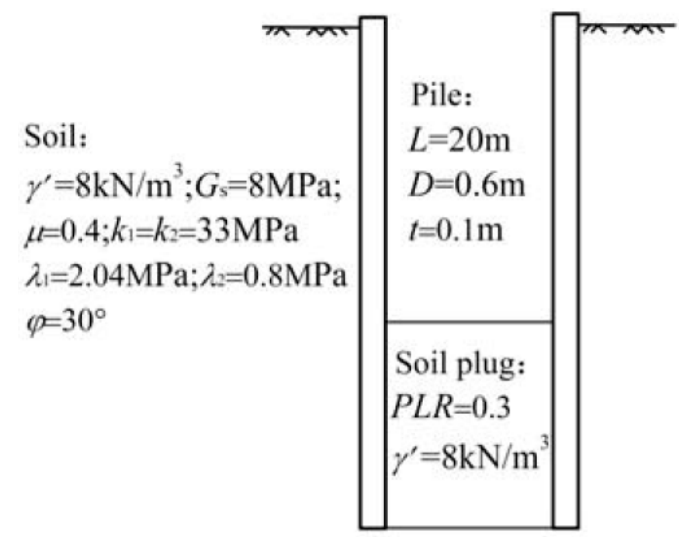

Figure 8. Sketch map of computing case.

Figure 9 shows the axial force along the pile shaft under different loadings on the pile top. As we can see, at the initial stage, the bearing capacity at the pile end was not stimulated, and only properties of the pure friction pile are shown. As load increased, working load at the pile end developed gradually, 
and the properties of the pile were in transition from the friction pile to bearing friction pile. Moreover, at the initial stages, the distribution of axial force was roughly linear, and then transformed into a curve, whose slopes got steeper as the depth became deeper. This revealed that the friction of the lower part of the pile was greater than that of the upper part. The slope in the vicinity of the pile end changed evidently. The larger the load, the more obvious the change in slope appeared. This meant that the axial force decreased sharply, largely due to the contribution of soil plug friction.

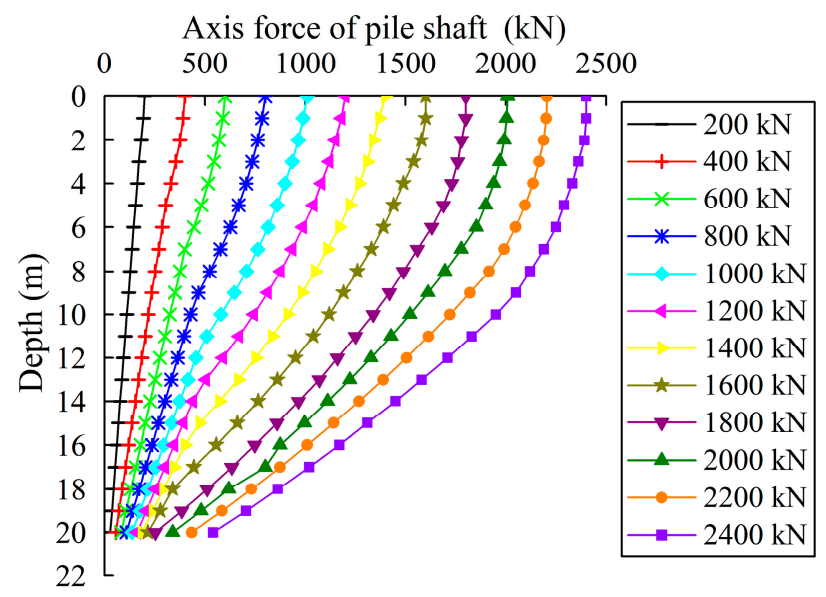

Figure 9. Distribution of axial force for open-ended pipe.

Figure 10 shows the distribution of the internal friction of pile annulus under each level of load. The distribution increased exponentially with depths. The closer it was to the pile end, the larger the friction. When the load was small, the frictional resistance provided by the soil plug was negligible. As the load increased, the frictional resistance was gradually stimulated and the effective height increased gradually as well. When the load was $2400 \mathrm{kN}$, the internal skin friction was approximately $500 \mathrm{kPa}$, which was roughly six times as large as the external skin friction in the same depth. The effective height of the soil plug was $2.03 D_{\mathrm{i}}$, which meant that the soil plug stress mainly lay close to the pile end. When the load was at its limit bearing capacity of $2150 \mathrm{kN}$, the internal skin friction at the pile end was $283 \mathrm{kN}$, which was 3.4 times as large as the external skin friction, and the effective height of the soil plug was $1.78 D_{\mathrm{i}}$. The analysis above demonstrated that, when the working load reached the bearing capacity limit, the part of the soil plug whose friction had been developed was only within the range of two inner radiuses above the pile end. The bearing capacity of the soil plug was far from well-developed, and the soil plug end resistance depended on the development of the lower part of the soil plug, which is inconsistent with the research result of Kishida and Isemoto [31].

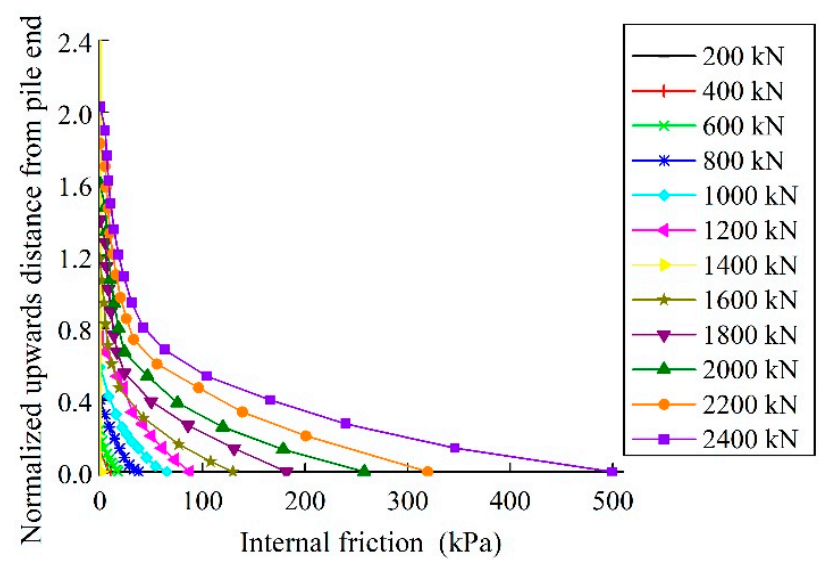

Figure 10. Distribution of internal skin friction under loading. 
Figure 11 shows how the ratio of end resistance to the load at the pile top of two kinds of pipe piles changed with increasing load. As we can see, end resistance remained steady when the load was less than $1700 \mathrm{kN}$, and the proportion of end resistance increased gradually when the load was greater than $1700 \mathrm{kN}$. When the load reached $2400 \mathrm{kN}$, the load at the open-ended pipe pile top shared by the pile annulus and soil plug accounted for $20.1 \%$ and $6.1 \%$, respectively. In comparison, the ratio of end-resistance to the load for the closed-ended pipe pile was $22.6 \%$, slightly less than that of the open-ended one. This was because the squeezing effect of the closed-ended pipe pile was more significant, so that the external skin friction was much greater than that of the open-ended pipe pile, which caused only part of the soil to be squeezed. Consequently, the proportion of the external skin friction of the closed-ended pile was larger.

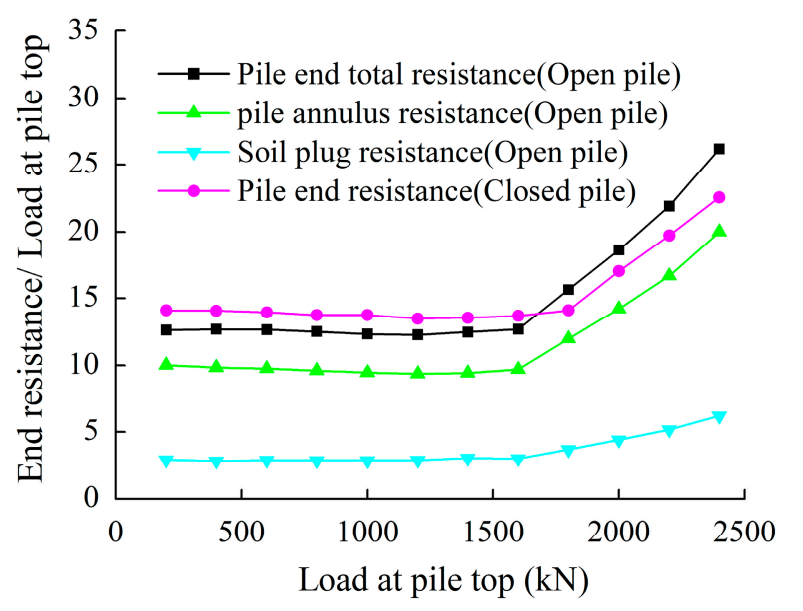

Figure 11. Change in the ratio of end resistance to load under loading.

Figure 12 shows the curves of load-displacement at the pile top of the open-ended and closed-ended piles under the same conditions. The two curves were almost overlapping at the initial loading stage, and when load exceeded $1700 \mathrm{kN}$, the two curves started to diverge. At the later stage of loading, the settlement of the closed-ended pipe pile was smaller than that of the open-ended one, and the larger the loading, the more apparent the difference. The load values of the closed-ended and open-ended pipe piles at the displacement level of $40 \mathrm{~mm}$ were $2331 \mathrm{kN}$ and $2150 \mathrm{kN}$, respectively, with the former being $8 \%$ greater than the latter.

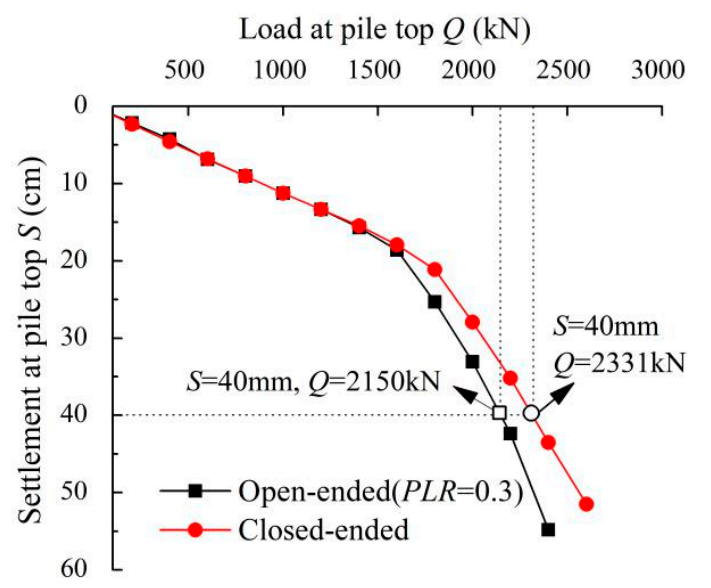

Figure 12. Curve of load-displacement at the pile top.

\section{Discrete Element Method Model}

The discrete element method (DEM) has been developed and has recently been used in geotechnical engineering. The DEM is based on the explicit numerical scheme in which the interaction of particles 
is modelled contact-by-contact and the relative motion of the particles is modelled particle-by-particle. Therefore, the DEM makes it possible to simulate granular materials at both the micro and macro scales, and the software PFC developed by the ITASCA consulting group was applied in this study. A model open-ended pipe pile was jacked into the homogeneous sandy soil samples generated using Grid-Method [34]. An increased gravity field of $100 \mathrm{~g}$ was conducted in this simulation, mimicking the centrifuge testing conditions, resulting in a prototype pile with a diameter of $4.5 \mathrm{~m}$ and penetration length of $50 \mathrm{~m}$. Each pile wall was made of two columns of overlapped particles with a radius of 1.125 $\mathrm{mm}$, so as to measure the external and inner friction separately. Table 1 shows the discrete element method model input parameters. The view of system just after installation is plotted in Figure 13, and the final length of the soil plugs was $0.24 \mathrm{~m}(\mathrm{PLR}=0.48)$. The sand particles were made of disks with a maximum diameter of $7.05 \mathrm{~mm}$, a minimum diameter of $4.5 \mathrm{~mm}$, an average grain diameter $d_{50}=5.85$ $\mathrm{mm}$ and uniformity coefficient $c_{u}=d_{60} / d_{10}=1.26$. The ratio of $d_{\text {pile }} / d_{50}$ was around 8 in this model, which is close to the values suggested by Vallejo and Lobo-Guerrero [35], ensuring the efficiency and accuracy of this numerical modelling.

Table 1. Input parameters for discrete element method (DEM) simulations.

\begin{tabular}{cc}
\hline Simulation Parameters & Value \\
\hline Density of sand particles $\left(\mathrm{kg} / \mathrm{m}^{3}\right)$ & 2650 \\
Density of particles for pile $\left(\mathrm{kg} / \mathrm{m}^{3}\right)$ & 500 \\
Average particle size $(\mathrm{mm})$ & 5.85 \\
Pile outer diameters $(\mathrm{mm})$ & 45 \\
Pile inner diameters $(\mathrm{mm})$ & 39.6 \\
Model pile length $(\mathrm{mm})$ & 500 \\
Model container width $(\mathrm{mm})$ & 1200 \\
Model container depth $(\mathrm{mm})$ & 600 \\
Friction coefficient of the particles & 0.5 \\
Friction coefficient of pile and walls & 0.5 \\
Young's modulus of particles $($ Pa) & $4 \times 10^{7}$ \\
Particle stiffness ratio $\left(k_{s} / k_{n}\right)$ & $8 \times 10^{7}$ \\
Contact normal stiffness of pile and particles $(\mathrm{N} / \mathrm{m})$ & 0.25 \\
Contact normal stiffness of walls $(\mathrm{N} / \mathrm{m})$ & $6 \times 10^{12}$ \\
Initial average porosity & 0.25 \\
Final average porosity (final equilibrium) & 0.185 \\
Bulk unit weight $\left(\mathrm{kN} / \mathrm{m}^{3}\right)$ & 2115.3 \\
\hline
\end{tabular}

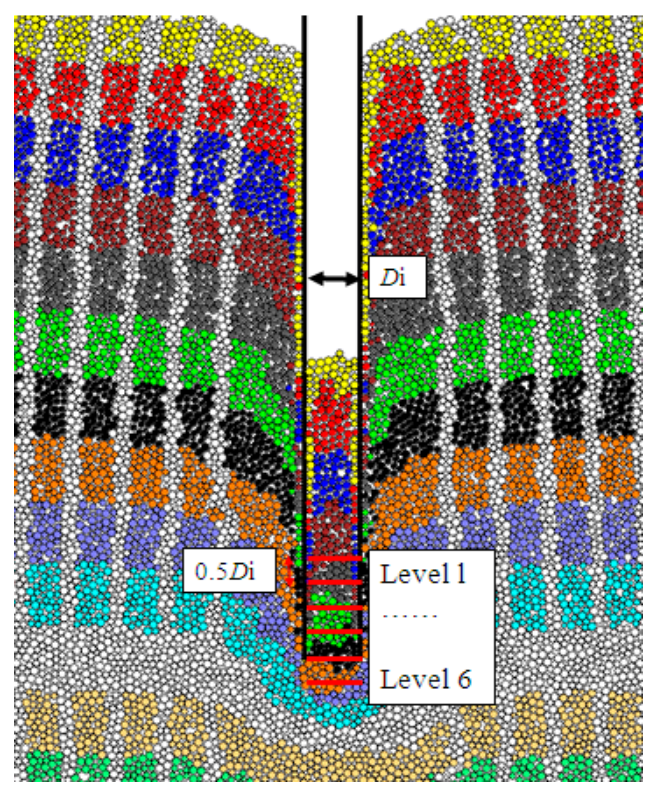

Figure 13. View of pile-soil system just after installation. 
After installation of the pile, the increasing vertical static loads were applied on the pile top until they reached the limited load (i.e., the pile top settlement reached to $10 \%$ of the pile outer diameter $D_{\mathrm{e}}$ ). It was noted that the residual stresses induced by the installation were ignored in this simulation. In order to compare the external and internal friction more clearly, only the section of $2.0 D_{\mathrm{i}}$ above the pile tip were considered, as shown in Figure 14. It was clear that both the internal and external skin frictions were gradually stimulated with increasing loads. The maximum internal skin friction at the pile end was $981 \mathrm{kPa}$, which was $50 \%$ larger than the maximum external skin friction. This ratio was close to the measurements in the piles with lower plugging degree $[8,10]$, but was much lower than that in the above calculation example (Section 3), probably due to its higher plugging degree. Meanwhile, the internal skin friction decayed sharply with the distance from the pile tip, decreasing to less than the corresponding external skin friction above $0.4 D_{\mathrm{i}}$. The effective height of the soil plug was $1.89 D_{\mathrm{i}}$ at the limited load, which was closed to the value of $1.78 D_{\mathrm{i}}$ obtained from the calculated example (Figure 10) and the observations from the model test [36]. The internal frictions and external frictions in this DEM model were normalized by the maximum internal friction at the pile end under limited load $Q_{\mathrm{L}}$, with a normalized distance from the pile end, which are plotted in Figures 15-18. It was clear that these distributions were close to the results from the analytical model.

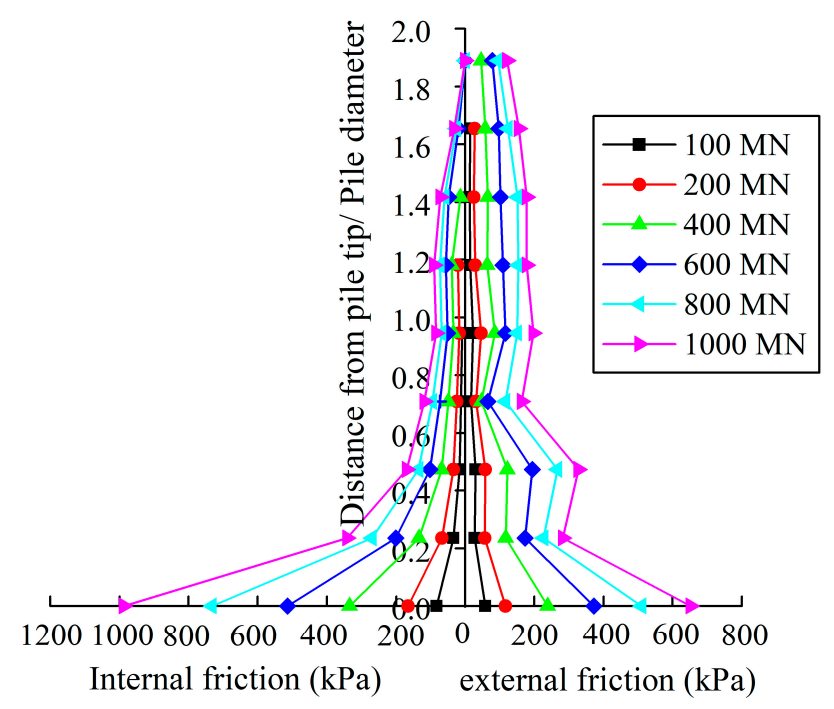

Figure 14. Comparison of internal and external skin friction under loading.

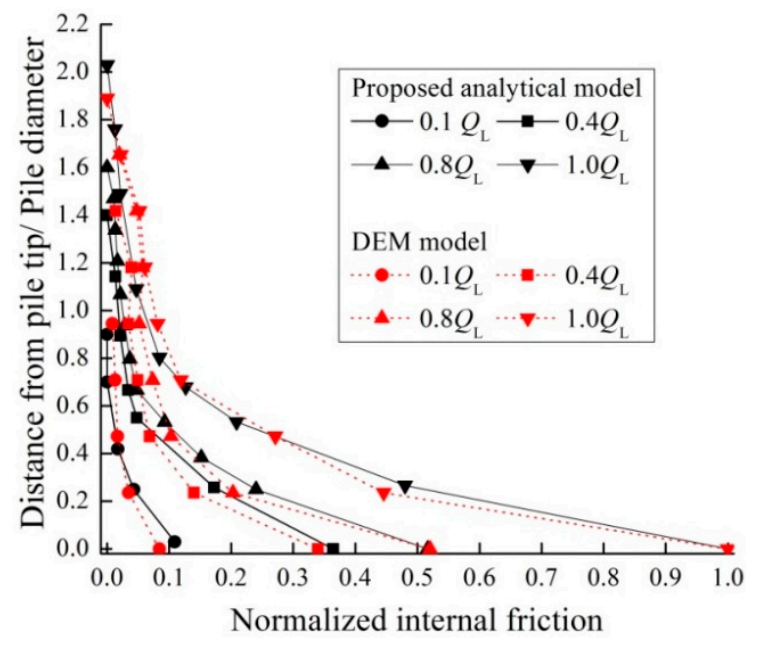

Figure 15. The internal friction from the analytical method and DEM model. 


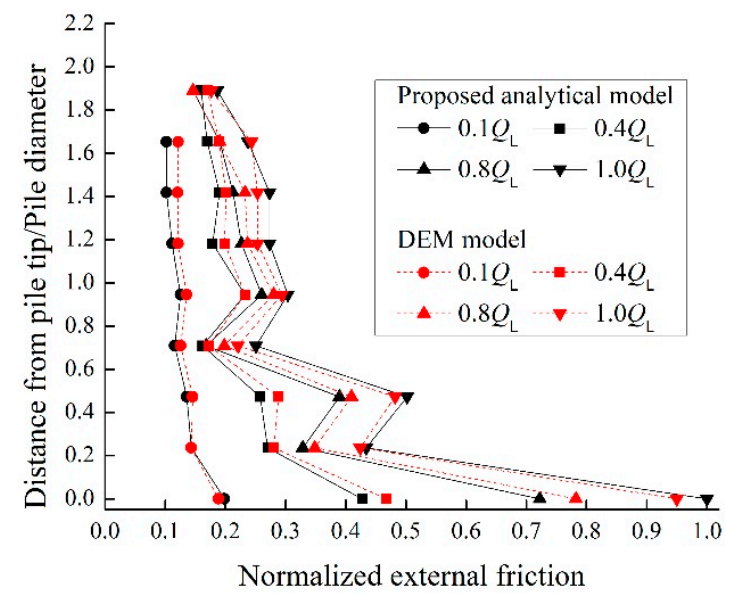

Figure 16. The external friction from the analytical method and DEM model.

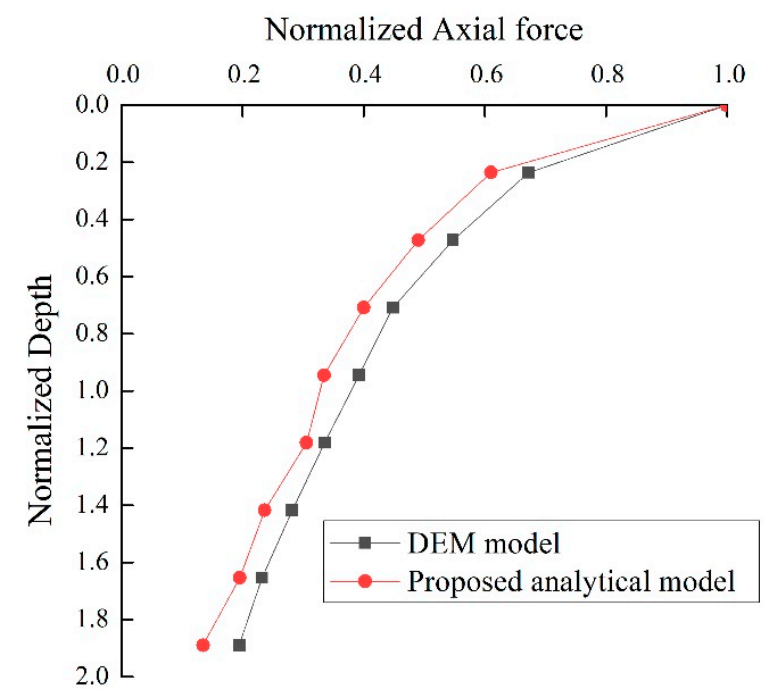

Figure 17. The axial force-depth from the analytical method and DEM model.

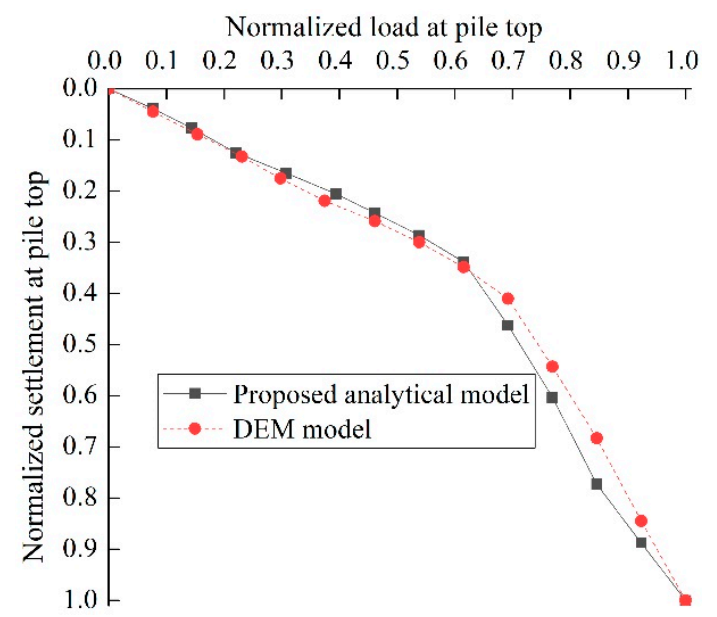

Figure 18. The load at pile top versus the settlement from the analytical method and DEM model.

The relative vertical displacements of sand particles from the pile tip at the limited load at six levels (at $0.5 D_{\mathrm{i}}$ intervals) inside the pile at the limited load are plotted in Figure 19. It was clear that the particles at level 2-6 moved upwards relative to the pile tip, partially at and beneath the pile tip level. This indicated that the soils beneath the pile tip still further intruded into the pipe with the pile tip settlement. Even so, as the particles at levels 1 remained relatively static, the soil plug 
length kept constant during the whole loading process, indicating that the soil plug was compacted. This phenomenon further confirmed that the effective height of the soil plug was the portion where the soil particles moved relative to pile wall. In addition, the particles around the central axis experienced larger displacements than the adjacent pile inner skin, thus implying an "initiative arch" formed under the restriction of internal skin friction during vertical loading.

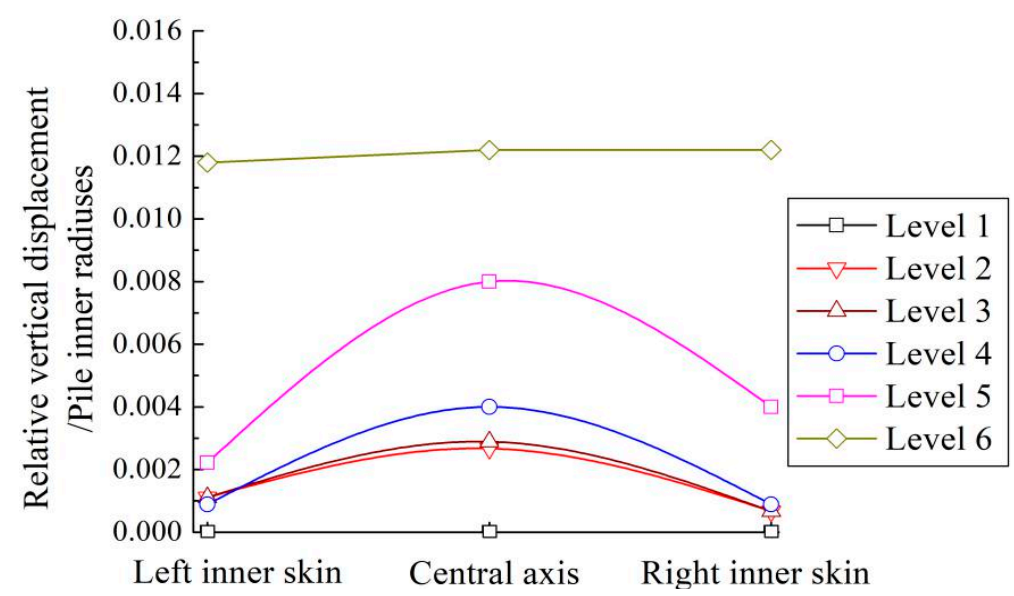

Figure 19. Relative vertical displacements at six levels inside the pile.

\section{Concluding Comments}

(1) The development mechanisms of internal and external skin frictions of open-ended pipe piles are different. While the inner soil plug was compressed during loading, the surrounding soil experienced mainly shearing deformation, and thus the external skin fiction was developed before the inside one. End resistance of the open-ended pile was shared by the pile annulus and soil plug.

(2) A kind of pile-in-pile load transfer model was established. In this model, a trilinear model was introduced to describe the load transfer at the pile-soil interface. A rigid plastic model was introduced to describe the load transfer at the pile-plug interface, and an equilibrium equation was proposed for the soil plug based on the hypothesis of a trilinear model for lateral pressure coefficient of a soil plug. A load transfer double broken line model was introduced to describe the load transfer at the pile end, done so by dividing the pile end resistance into two parts shared by the soil plug and pile annulus, respectively.

(3) The calculation example showed that the end resistance of the open-ended pile was shared mainly by pile annulus, with the proportion increasing with increasing load at the pile top. Soil plug friction was accumulated within the range of two inner radiuses above the pile end, and soil plug friction at the pile end was 3.4 times as large as the external skin friction. The bearing capacity of open-ended piles was smaller than that of closed-ended ones under the same conditions.

(4) The discrete element method model, mimicking the centrifuge testing conditions, revealed a similar load transfer process to the calculation example. Soil plug friction was generally mobilized with increasing loads, and extended upward to 1.89 inner radiuses (effective height) at a limited load. The soils beneath the pile tip intruded into pile pipe during the loading process, compacting the soil plug and thus causing the internal skin friction at the pile end to be $50 \%$ higher than the corresponding external skin friction.

Author Contributions: Conceptualization, J.L. and Z.G.; methodology, J.L.; validation, J.L., B.H. and Z.G.; formal analysis, Z.G.; investigation, B.H.; resources, J.L.; data curation, J.L.; writing-original draft preparation, J.L.; writing-review and editing, Z.G.; visualization, Z.G.; supervision, J.L.; funding acquisition, J.L.

Funding: This research was funded by National Natural Science Foundation of China $(41772318,51779220)$, Qingdao Fundamental Research Project (16-5-1-34-jch), Shandong Key Research and Development Plan (2017GSF20107), Open Fund of State key Laboratory of Coastal and Offshore Engineering (LP1712) and Ministry of Housing and Urban-Rural Development of China (2014-K3-026). 
Conflicts of Interest: The authors declare no conflicts of interest.

\section{References}

1. Randolph, M.F.; Cassidy, M.; Gourvenec, S.M. Challenges of offshore geotechnical engineering. In Proceedings of the 16th International Conference on Soil Mechanics and Geotechnical Engineering, Osaka, Japan, 12-16 September 2005; Plenary Session D; Millpress Science Publishers: Rotterdam, The Nertherlands, 2005.

2. Randolph, M.F.; Gaudin, C.; Gourvenec, S.M.; White, D.J.; Boylan, N.; Cassidy, M.J. Recent advances in offshore geotechnics for deep water oil and gas developments. Ocean Eng. 2011, 38, 818-834. [CrossRef]

3. Guo, Z.; Jeng, D.S.; Zhao, H.Y.; Guo, W.; Wang, L.Z. Effect of seepage flow on sediment incipient motion around a free spanning pipeline. Coast. Eng. 2019, 143, 50-62. [CrossRef]

4. Li, K.; Guo, Z.; Wang, L.Z.; Jiang, H.Y. Effect of seepage flow on shields number around a fixed and sagging pipeline. Ocean Eng. 2019, 172, 487-500. [CrossRef]

5. Liu, J.W.; Duan, N.; Cui, L.; Zhu, N. DEM investigation of installation responses of jacked open-ended piles. Acta Geotech. 2019. [CrossRef]

6. Randolph, M.F.; Leong, E.C.; Houlsby, G.T. One dimensional analysis of soil plugs in pipe piles. Geotechnique 1991, 41, 587-598. [CrossRef]

7. Yu, F.; Yang, J. Base Capacity of Open-Ended Steel Pipe Piles in Sand. J. Geotech. Geoenviron. Eng. 2012, 138, 1116-1128. [CrossRef]

8. Ko, J.; Jeong, S. Plugging effect of open-ended piles in sandy soil. Can. Geotech. J. 2015, 52, 535-547. [CrossRef]

9. Byrne, B.W. Drive pipe piles in dense sand. In Australian Geomechanics; Paper No.9501; Geonechanics Group: Perth, Australia, 1995; pp. 72-80.

10. Paik, K.; Salgado, R.; Lee, J.; Kim, B. Behavior of open and closed-ended piles driven into sands. J. Geotech. Geoenviron. Eng. 2003, 129, 296-306. [CrossRef]

11. Jardine, R.J.; Chow, F.C.; Overy, R.; Standing, J. ICP Design Methods for Driven Piles in Sands and Clays; Thomas Telford: London, UK, 2005.

12. Gavin, K.; Lehane, B. Base load-displacement response of piles in sand. Can. Geotech. J. 2007, 44, $1053-1063$. [CrossRef]

13. Liu, J.W.; Guo, Z.; Zhu, N.; Zhao, H.; Garg, A.; Xu, L.F.; Liu, T.; Fu, C.C. Dynamic response of offshore open-ended pile under lateral cyclic loadings. J. Mar. Sci. Eng. 2019, 7, 128. [CrossRef]

14. Randolph, M.F. Science and empiricism in pile foundation design. Géotechnique 2003, 53, 847-875. [CrossRef]

15. Murff, J.D.; Raines, R.D.; Randolph, M.F. Soil plug behaviour of piles in sand. In Proceedings of the 22nd Offshore Technology Conference, OTC 6421, Houston, TX, USA, 7-10 May 1990; pp. 25-32.

16. Paikowsky, S.G.; Whitman, R.V.; Baligh, M.M. A new look at the phenomenon of offshore pile plugging. Mar. Geotechnol. 1990, 8, 213-230. [CrossRef]

17. Randolph, M.F.; Wroth, C.P. Analysis of deformation of vertically loaded piles. J. Geotech. Eng. Div. 1978, 104, 1465-1488.

18. Randolph, M.F. RATZ Program Manual: Load Transfer Analysis of Axially Loaded Piles; Dept. of Civil and Resource Engineering, University of Western Australia: Perth, Australia, 2003.

19. O’Neill, M.; Raines, R. Load Transfer for Pipe Piles in Highly Pressured Dense Sand. J. Geotech. Eng. 1991, 117, 1208-1226. [CrossRef]

20. Lehane, B.; Randolph, M. Evaluation of a Minimum Base Resistance for Driven Pipe Piles in Siliceous Sand. J. Geotech. Geoenviron. Eng. 2002, 128, 198-205. [CrossRef]

21. Yu, F.; Yang, J. Improved evaluation of interface friction on steel pipe pile in sand. J. Perform. Constr. Facil. 2012, 26, 170-179. [CrossRef]

22. White, D.J.; Sidhu, H.K.; Finlay, T.C.R.; Bolton, M.D.; Nagayama, T. Press-in piling: The influence of plugging on driveability. In Proceedings of the 8th International Conference of the Deep Foundations Institute, New York, NY, USA, 5-7 October 2000; pp. 299-310.

23. Lehane, B.M.; Gavin, K. Base resistance of jacked pipe piles in sand. J. Geotech. Geoenviron. Eng. 2001, 127, 473-480. [CrossRef]

24. Jeong, S.; Ko, J.; Won, J.; Lee, K. Bearing capacity analysis of open-ended piles considering the degree of soil plugging. Soils Found. 2015, 55, 1001-1014. [CrossRef] 
25. Zhang, Z.M. Pile Foundation Engineering; China Architecture \& Building Press: Beijing, China, 2007. (In Chinese)

26. Liu, J.W. Experimental and Theoretical Studies on the Construction Effects for Jacked Open-Ended Concrete Pipe Piles. Ph.D. Thesis, Zhejiang University, Hangzhou, China, 2012. (In Chinese).

27. Paik, K.; Salgado, R. Determination of Bearing Capacity of Open-Ended Piles in Sand. J. Geotech. Geoenviron. Eng. 2003, 129, 46-57. [CrossRef]

28. Yu, F.; Zhang, Z.M. A design framework for evaluating the vertical bearing capacity of open-ended concrete pipe pile from empirical correlations. China Civ. Eng. J. 2011, 44, 100-110. (In Chinese)

29. Randolph, M.F. Modelling of the soil plug response during pile driving. In Proceedings of the 9th SE Asian Geotechnical Conference, Bangkok, Thailand, 7-11 December 1987; pp. 6.1-6.14.

30. Liu, J.W.; Zhang, Z.Z.; Yu, F. Case history of installing instrumented jacked open-ended piles. J. Geotech. Geoenviron. Eng. 2012, 12, 810-820. [CrossRef]

31. Kishida, H.; Isemoto, N. Behaviour of sand plugs in open-end steel pipe piles. In Proceedings of the 9th International Conference Soil Mechanics, Tokyo, Japan, 10-15 July 1977; pp. 601-604.

32. Paik, K.H.; Lee, S.R. Behavior of soil plugs in open-ended model piles driven into sands. Mar. Georesour. Geotechnol. 1993, 11, 353-373. [CrossRef]

33. De Nicola, A.; Randolph, M.F. The plugging behavior of driven and jacked piles in sand. Geotechnique 1997, 47, 841-856. [CrossRef]

34. Duan, N.; Cheng, Y.P. Discrete Element Method Centrifuge Model of Monopile under Cyclic Lateral Loads. Int. J. Environ. Chem. Ecol. Geol. Geophys. Eng. 2016, 10, 200-205.

35. Vallejo, L.; Lobo-Guerrero, S. DEM analysis of crushing around driven piles in granular materials. Géotechnique 2005, 55, 617-623.

36. Kumara, J.J.; Kikuchi, Y.; Kurashina, T. Effective Length of the Soil Plug of Inner-Sleeved Open-Ended Piles in Sand. J. GeoEng. 2015, 10, 75-82.

(C) 2019 by the authors. Licensee MDPI, Basel, Switzerland. This article is an open access article distributed under the terms and conditions of the Creative Commons Attribution (CC BY) license (http://creativecommons.org/licenses/by/4.0/). 